\title{
O empreendedorismo como uma ideologia neoliberal
}

\author{
LUANA JÉSSICA OLIVEIRA CARMO ${ }^{1}$ \\ LILIAN BAMBIRRA DE ASSIS ${ }^{1}$ \\ ADMARDO BONIFÁCIO GOMES JÚNIOR ${ }^{1}$ \\ MarCella Barbosa Miranda TEIXEIRA ${ }^{1}$ \\ ${ }^{1}$ Centro Federal de Educação Tecnológica de Minas Gerais (CEFET-MG) / Programa de Pós-Graduação em Administração,
} BELO HORIZONTE - MG, BRASIL

\section{Resumo}

Este ensaio crítico tem como objetivo geral compreender a vertente neoliberal dos discursos do empreendedorismo e sua função de camuflagem da realidade das relações entre trabalho e capital. Baseando-se no pressuposto de que os discursos do empreendedorismo são depositários de uma ideologia neoliberal, analisa-se o desenvolvimento histórico do conceito e do seu campo de estudo; qualifica-se o caráter neoliberal do empreendedorismo; caracteriza-se o aparato teórico que sustenta e dissemina o empreendedorismo. O estudo conclui, criticamente, que o discurso do empreendedorismo isenta o Estado da responsabilidade de garantir mínimas condições de vida para os trabalhadores, colocando-os como responsáveis pelo seu sucesso ou fracasso, independentemente da importância das variáveis do contexto social.

Palavras-chave: Empreendedorismo. Ideologia neoliberal. Crítica.

\section{Entrepreneurship as a neoliberal ideology}

\section{Abstract}

This critical essay has the general objective of understanding the neoliberal aspect of entrepreneurship's discourses and its function of camouflaging the reality of the relations between work and capital. This research analyzes the historical development of the concept and its field of study based on the assumption that these narratives are depositories of a neoliberal ideology. The research discusses the neoliberal nature of entrepreneurship and characterizes the theoretical apparatus that supports and disseminates entrepreneurship. Finally, the results critically point out that entrepreneurship's discourse exempts the state from the responsibility of guaranteeing minimum living conditions for workers, meaning they are responsible for their success or failure, regardless of the importance of social context variables.

Keywords: Entrepreneurship. Neoliberal ideology. Criticism.

\section{El emprendimiento como ideología neoliberal}

\section{Resumen}

Este ensayo crítico tiene el objetivo general de comprender el aspecto neoliberal de los discursos del emprendimiento y su función de camuflaje de la realidad de las relaciones entre trabajo y capital. Partiendo del supuesto de que los discursos del emprendimiento son depositarios de una ideología neoliberal, se analiza el desarrollo histórico del concepto y su campo de estudio; se califica el carácter neoliberal del emprendimiento; y se caracteriza el aparato teórico que apoya y difunde el emprendimiento. El estudio concluye, críticamente, que el discurso del emprendimiento exime al Estado de la responsabilidad de garantizar condiciones mínimas de vida a los trabajadores, ubicándolos como responsables de su éxito o fracaso, independientemente de la importancia de las variables del contexto social.

Palabras clave: Emprendimiento. Ideología neoliberal. Crítica. 


\section{INTRODUÇÃO}

Semanticamente, os termos "empreendedorismo" e "empreendedor" vêm da palavra francesa "entrepreneur", que tem origem no latim "imprehendere". Hoselitz (1951) buscou o significado no dicionário de língua francesa, de E. Littré, que traz a seguinte definição: "celui qui entreprend qualque chose", ou seja, aquele que empreende, se encarrega ou se compromete com alguma coisa. Assim, empreendedor pode ser entendido como aquela pessoa que se encarrega de fazer algo, que faz alguma construção ou outra coisa (Boava \& Macedo, 2009; Hoselitz, 1951; Vale, 2014).

Do ponto de vista social, a atividade do empreendedor é tão antiga quanto o intercâmbio e o comércio entre os indivíduos na sociedade (Landström, Harirchi \& Aström, 2012). Entretanto, somente em 1770 o termo foi utilizado para se referir a alguém que controla uma empresa (Vale, 2014). De acordo com Landström et al. (2012), o conceito ganhou importância com a emergência dos mercados capitalistas e com a evolução das fábricas e manufaturas (Landström et al., 2012; Vale, 2014; Verga \& Silva, 2014).

A evolução do conceito revela uma transformação social, refletindo a passagem de uma sociedade antes caracterizada pela produção manufatureira e agrária para uma produção mercantil, industrial, até chegar até chegar aos modelos de produção contemporânea. A história do empreendedorismo acompanha a história das instituições e costumes, que foram evoluindo de acordo com as novas realidades. Desse modo, o conceito e as definições de empreendedorismo foram se transformando ao longo da história e adquirindo novos significados (Hoselitz, 1951; Vale, 2014).

Com o decorrer do tempo, o empreendedorismo tornou-se objeto de diversos estudos. Isso levou pesquisadores a se esforçarem para traçar as perspectivas do empreendedorismo, elaborando uma estrutura conceitual. Diversas perspectivas foram traçadas por diferentes autores sobre o empreendedorismo, contudo, a comunidade científica ainda não alcançou um consenso acerca do assunto (Landström et al., 2012; Shane \& Venkataraman, 2000). A história mostra que o empreendedorismo recebeu contribuições de variados campos, o que resultou em definições complexas e diferentes para um mesmo fenômeno. Machado e Nassif (2014) consideram o empreendedorismo como uma perspectiva de estudo ainda em construção.

Desde a década de 1970, concebida como um marco para o empreendedorismo, o conceito tornou-se alvo de interesse do campo de estudos da gestão e se disseminou por meio de discursos que o elegem como uma solução para a crise do desemprego. Neste raciocínio, o desemprego não é visto mais como um problema social, mas como resultante de uma falha do indivíduo por não conseguir se adaptar às organizações (Gaulejac, 2007). Esse tipo de discurso, que atribui a responsabilidade ao indivíduo, teve maior proeminência no Brasil a partir da década de 1990, com a eleição de Fernando Collor e as mudanças políticas e econômicas pautadas na transição da agenda constitucional reformista para uma agenda competitiva (Cordeiro \& Mello, 2006).

Tais mudanças políticas se refletem no aumento expressivo da taxa de empreendedorismo no Brasil. Em 2018, segundo o Global Entrepreneurship Monitor (GEM) Brasil, a taxa total do empreendedorismo brasileiro (TTE) foi de 38\%, o que corrresponde a cerca de 52 milhões de brasileiros com idade entre 18 e 64 anos envolvidos em algum negócio como empreendedor, em estágio inicial ou estabelecido. De acordo com isso, de cada cinco brasileiros adultos, dois se declaram como empreendedores. Comparativamente, em 2002 esse número era de 14,4 milhões, correspondendo à taxa de 13,5\%. É importante ressaltar que o Relatório GEM "[...] identifica como empreendedores as pessoas que criaram ou estão criando qualquer tipo de empreendimento, mesmo aqueles mais simples, gerados pela necessidade de subsistência" (GEM Brasil, 2018, p. 9).

O que se percebe no Brasil é um empreendedorismo de subsistência sustentado por pequenos negócios, já que cerca de $82 \%$ dos negócios iniciais e estabelecidos não possuem nenhum empregado, ou seja, envolvem apenas um empreendedor individual. Outra característica que sustenta esta interpretação é a estimativa de renda dos empreendedores: segundo o GEM Brasil (2018), a metade desses negócios tem um faturamento de até $\mathrm{R} \$ 12$ mil por ano, o que representa cerca de um salário mínino por mês. Para Tavares (2018), o empreendedorismo é uma categoria de trabalho informal, que, com o discurso da autonomia, coloca o sujeito empreendedor como patrão e com a oportunidade de ascensão social.

Contudo, do ponto de vista da relação conflituosa entre capital e trabalho, característica do capitalismo, entende-se que o empreendedorismo consiste em uma ideologia depositária de uma racionalidade neoliberal, cuja forma de disseminação por meio de discursos, imperativos e normas de conduta, acaba por naturalizar sua forma de dominação. A racionalidade neoliberal destrói regras, instituições e direitos para produzir certas formas de viver e de se relacionar com os outros e, por 
meio disso, fabricar um novo sujeito (Dardot \& Laval, 2016). Assim, a racionalidade neoliberal, oriunda do novo espírito capitalista, sustenta-se sobre dois pilares: a competição generalizada que transforma sujeitos em homens-empresa, aptos a se comportarem segundo os valores mercantis; e a conversão generalizada dos meios em fins operacionalizada pelo gerenciamento, cujo discurso do management converte os homens em meros instrumentos produtivos e os resultados financeiros em fins (Gaulejac, 2007).

A concepção do empreendedorismo como uma ideologia pode ser justificada de diversas perspectivas. Uma delas é representada pelas inexoráveis harmonias das teorias administrativas abordadas por Tragtenberg - essa "harmonia" entre capital e trabalho foi disseminada desde os estudos clássicos da administração: Taylor, Ford, Fayol. A partir da década de 1970, as mudanças no paradigma produtivo, influenciadas pelo modelo japonês de produção, trouxeram novas configurações do perfil do trabalhador: flexibilidade, conhecimento, autocontrole e polivalência, e juntamente com estas capacidades a ideia de participação nas decisões da empresa. A forma mais atual desta harmonia nas teorias administrativas é o empreendedorismo, no qual o sujeito deve ser o empreendedor de si (Oviedo \& Misoczky, 2017; Paes de Paula, 2002).

Diante do contexto, este ensaio crítico tem como objetivo geral compreender a vertente neoliberal dos discursos do empreendedorismo e sua função de camuflagem da realidade das relações entre trabalho e capital. Para isso, busca-se um resgate histórico do empreendedorismo e uma pesquisa mais aprofundada sobre a evolução do campo, o que culminou em um olhar crítico sustentado pelos discursos aparentemente harmônicos que se disseminam em torno da ideia do empreendedorismo.

\section{As Eras do Pensamento Empreendedor}

A história do empreendedorismo pode ser distinguida em três grandes eras de pensamento, conforme a Figura 1.

Figura 1

As três eras do Pensamento Empreendedor

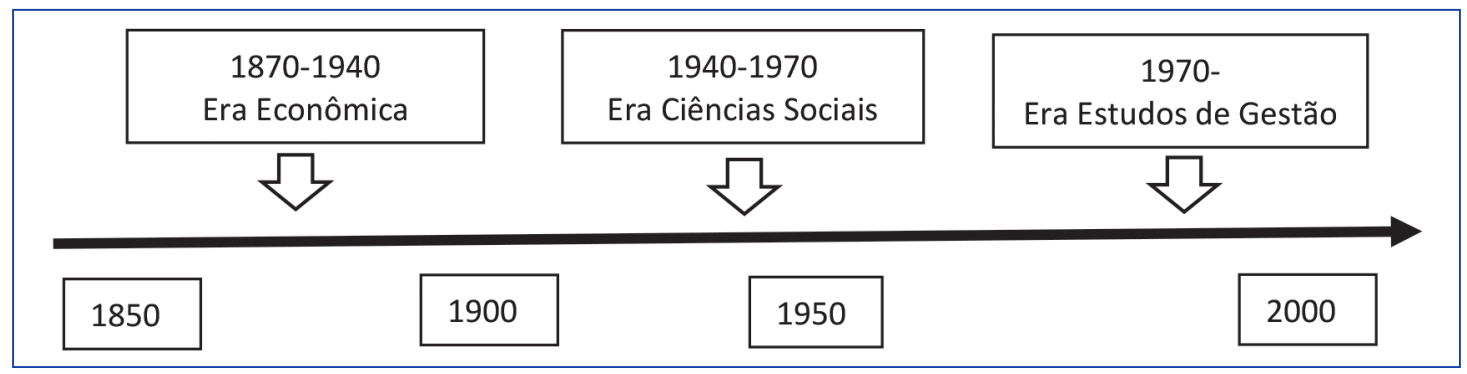

Fonte: Landström e Benner (2010 como citado em Verga \& Silva, 2014, p. 7).

A Era Econômica (1870-1940) inicia-se com os estudos de Cantillon, continua com Say, Knight, Schumpeter, até chegar à Escola Austríaca. A Era das Ciências Sociais (1940-1970) foi marcada por estudos sobre o empreendedor como indivíduo, e recebeu a contribuição de psicólogos e sociólogos. Os psicólogos estudavam os traços de personalidade do empreendedor, enquanto os sociólogos voltavam-se para o seu papel na mudança social. Surgiram, então, as questões a respeito dos pressupostos filosóficos, dos princípios ontológicos e epistemológicos (Verga \& Silva, 2014). A Era dos Estudos de Gestão, iniciada na década de 1970 e vigente até os dias atuais, tem sido marcada por mudanças políticas, econômicas e tecnológicas, o que torna o empreendedorismo um tema dominante na sociedade (Verga \& Silva, 2014).

Há certo consenso entre os pesquisadores em considerar Richard Cantillon e Jean-Baptiste Say como os primeiros a utilizarem o termo empreendedor. Cantillon afirma que, assim como os agricultores a artesãos, todos aqueles que trabalham por sua conta e risco são considerados empreendedores. Ele ainda descreve que alguns ficam ricos e ganham mais que o dobro de sua subsistência, enquanto outros acabam arruinados e quebrados (Cantillon, 1950).

Em sua obra, Cantillon diferencia o empreendedor do capitalista, sendo o primeiro alguém que assume riscos e o último, aquele que fornece o capital. Para Cantillon, o empreendedor é ainda um decisor racional que assume o risco e gere a sua empresa com o objetivo de alcançar o lucro (Carvalho \& Costa, 2015). 
Para Say, que publicou a sua obra em 1803, o empreendedor era um mediador, um coordenador, que combinava diferentes fatores de produção, de maneira a produzir um determinado bem (Vale, 2014). Say ainda afirma que o empreendedor era aquele que transferia recursos econômicos de um setor de produtividade mais baixa para um setor de produtividade mais elevada e de maior rendimento (Carvalho \& Costa, 2015; Drucker, 1987). Say defendia que o sistema produtivo era representado por três funções diferentes: pelo especialista que produz conhecimentos; pelo empreendedor que põe os conhecimentos em prática para produzir novas utilidades e pelo operário que executa a operação produtiva. Assim, o empreendedor era basicamente um mediador entre o conhecimento e a execução (Dardot \& Laval, 201).

Nesse sentido, o empreendedor desempenhava o papel de coordenação entre a produção e a distribuição de um produto ou serviço, combinando os fatores de produção para resultar em novos empreendimentos. A definição da função de coordenação é considerada uma das principais contribuições de Say para o histórico do empreendedorismo (Carvalho \& Costa, 2015; Verga \& Silva, 2014).

Já em meados do século XX, a economia consolidou-se como disciplina, o que dificultou a inclusão de estudos sobre o empreendedor em seus modelos. Na década de 1940, uma série de estudos ancorados na economia e na história voltaram a se debruçar novamente pelo empreendedorismo, principalmente no Centro de Pesquisa em História Empresarial da Universidade de Harvard. Os estudos pautavam-se na abordagem shumpeteriana, focando os processos de modernização das sociedades em todo o mundo (Landström et al., 2012).

O economista Joseph Schumpeter aspirava construir uma nova teoria econômica pautada na mudança e na inovação. Para ele, o crescimento econômico não foi resultado da acumulação de capital, mas sim de novas combinações, as inovações (Landström et al., 2012). Desta perspectiva, ele define que o papel do empreendedor é reformar ou revolucionar o sistema de produção por meio de novas possibilidades (Schumpeter, 1961). Schumpeter considera empreendedores somente aqueles que reformam e revolucionam o sistema produtivo (Bruyat \& Julien, 2001).

O economista austríaco reposiciona o empreendedor no centro do processo econômico, atribuindo a ele a responsabilidade pela "destruição criativa" (Schumpeter, 1961), a qual consiste em um processo orgânico em permanente mutação e que "[...] incessantemente revoluciona a estrutura econômica de dentro, destruindo a velha e criando uma nova estrutura" (Leite, 2012, p. 28).

Já na década de 1960, a psicologia e a sociologia passaram a estudar o perfil do empreendedor baseadas em suas características comportamentais. O principal expoente desses estudos foi David McClelland, com sua obra The Achieving Society (1961) (Filion, 1999; Landström et al., 2012). McClelland (1961) afirmava que o empreendedor era aquele que produzia uma quantidade além do seu consumo pessoal.

Com base na obra de Weber, McClelland sugeriu que o espírito do capitalismo moderno carregava consigo um sistema de valores que motivava os indivíduos à autorrealização. Os mecanismos psicológicos que intervêm nesses valores são associados ao protestantismo ou ao industrialismo moderno, como a educação e o treinamento para a independência dos filhos respectivamente (Leite, 2012). McClelland buscou mostrar que a base do comportamento do empreendedor era moldada pelo ambiente, pela necessidade de realização; não decorria de aspectos genéticos do indivíduo. Para o autor, a necessidade de realização que impulsionava o desenvolvimento econômico de uma região se desenvolveria por meio da cultura, das experiências e da aprendizagem. O empreendedor era, para McClelland, um produto do meio (Barlach, 2014).

\section{O Empreendedorismo a partir da Década de 1970}

As décadas de 1960 e 1970 foram caracterizadas por grandes mudanças econômicas na sociedade. As mudanças ocasionadas pela tecnologia impactaram indústrias, grandes empresas e até os pequenos negócios. Nesse mesmo período, houve mudanças políticas nos Estados Unidos da América e no Reino Unido, principalmente influenciadas por políticos como Ronald Reagan e Margaret Thatcher, que afetaram a dinâmica mundial. Com estas mudanças, o empreendedorismo veio à tona novamente e se tornou um tema dominante na sociedade (Landström et al., 2012).

Baseadas na lógica de mercado que vigorava nos Estados Unidos, as mudanças se espalharam pelo mundo, e também chegaram ao Brasil a partir do início da década de 1990 com a eleição de Fernando Collor de Melo para a presidência. A agenda constitucional reformista foi alterada para a agenda competitiva, o que fez o Estado perder sua força na regulação da economia e abrir espaço para a ascensão do liberalismo (Cordeiro \& Mello, 2006). 
O acirramento da competitividade caracterizado pela globalização ocasionou a demissão de muitos empregados, principalmente em empresas que, diante da competição mundial, não conseguiram se manter no mercado. Sem muitas expectativas quanto ao mercado formal de trabalho, essas pessoas acabavam abrindo seu próprio negócio e se tornando "empreendedores", muitas vezes informais (Dornelas, 2008). Tais mudanças forçaram o desenvolvimento, no Brasil, de políticas voltadas para o empreendedorismo (Natividade, 2009).

No cenário brasileiro surgiram tanto iniciativas ofensivas, quanto defensivas em relação ao empreendedorismo individual e de pequeno porte (Colbari, 2015). A tendência de novos empregos serem gerados por pequenas e novas empresas já havia sido observada anteriormente nos Estados Unidos. O trabalho seminal de David Birch, The Job Generation Process, publicado em 1979, concluiu que a maioria dos novos empregos norte-americanos eram gerados por pequenas e novas empresas, o que impactou não apenas as pesquisas relacionadas ao empreendedorismo, mas também as decisões políticas, enquadrando decididamente as pequenas empresas nas análises de desenvolvimento econômico (Landström et al., 2012).

Na década de 1990, houve um aumento no número de periódicos e conferências voltados ao empreendedorismo, além de um aumento também de programas de educação e empreendedorismo. Com o intuito de entender melhor o fenômeno, houve uma entrada significativa de novos pesquisadores no campo. Essa mobilidade dentro e fora do campo tornou a pesquisa ainda mais fragmentada, principalmente em relação à estrutura teórica do empreendedorismo (Landström et al., 2012), motivo que levou os pesquisadores Shane e Venkataraman (2000) a caracterizarem a pesquisa em empreendedorismo como uma miscelânea. Academicamente, é possível reconhecer dois tipos de pesquisadores do empreendedorismo: de um lado, um grupo voltado para os estudos de gestão; e de outro, um grupo disperso de estudiosos de diversas disciplinas que realizam estudos pontuais sobre o empreendedorismo (Landström et al., 2012).

\section{O Empreendedorismo como uma Ideologia Neoliberal}

Como explicar que de um momento para o outro surja tanta gente disposta a trabalhar como doida por longos anos e enfrentar sérios riscos em vez de ter a segurança das grandes organizações? (Drucker, 1987).

Há indícios de que a resposta à pergunta de Peter Drucker pode ser encontrada nos discursos do empreendedorismo como uma ideologia neoliberal. Boava e Macedo $(2009$, p. 2) apresentam a seguinte definição para o termo:

Empreendedorismo é composto de empreendedor + ismo. Empreendedor é aquele que empreende. O sufixo ismo, em formas atuais, é utilizado para designar movimentos sociais, ideológicos, políticos, opinativos, religiosos e personativos. Trata-se da tomada de um partido, uma posição, um sistema, uma filosofia, uma circunstância.

Os discursos do empreendedorismo, pautados por uma racionalidade neoliberal, apregoam o estímulo à competição e ao individualismo, dentre outros valores mercantis, como forma de alcançar o "sucesso" (Dardot \& Laval, 2016), camuflando a precarização e a flexibilização do trabalho. $O$ sistema capitalista tem a necessidade de se renovar constantemente e o faz por meio de ideologias que Ihe conferem sentido. Essas ideologias sustentam o chamado "espírito do capitalismo", conjunto de crenças que contribuem para justificar e sustentar a ordem capitalista, legitimando ações e estilos de vida coerentes com ela (Boltanski \& Chiapello, 2009).

O capitalismo é indissociável da história de suas metamorfoses, de seus descarrilamentos, das lutas que o transformam, das estratégias que o renovam (Dardot \& Laval, 2016). A condição atual que sustenta o sistema capitalista é conhecida como neoliberalismo. Dardot e Laval (2016, p. 17) entendem o neoliberalismo como uma "[...] racionalidade, capaz de estruturar não só a ação dos governantes, como também as condutas dos governados". O neoliberalismo configura-se como um conjunto de discursos, práticas e dispositivos que determinam um novo modo de governo dos homens segundo o princípio universal da concorrência. A oposição entre Estado e mercado surge como um dos principais obstáculos à caracterização exata do neoliberalismo (Dardot \& Laval, 2016).

O neoliberalismo transformou profundamente o capitalismo e a sociedade. Nesse sentido, o neoliberalismo não é apenas uma ideologia, mas um tipo de política econômica, um sistema normativo que expandiu sua influência ao mundo inteiro, estendendo a lógica do capital a todas as relações sociais e esferas da vida (Dardot \& Laval, 2016). 
Dessa forma, o empreendedorismo é considerado uma estratégia do capitalismo, cujo discurso posiciona o empreendedor como um agente de crescimento econômico e de mudança social. Na visão neoliberal, "[...] o empreendedorismo é uma estratégia pela qual é transferida ao trabalhador a atribuição de gerar postos de trabalho, de modo a garantir 'ordem e progresso' capitalistas" (Tavares, 2018, p. 110). A autora ainda completa:

O Estado limitado ou Estado mínimo, na verdade, constitui uma hipertrofia; o mercado, por sua vez, adquire uma dimensão gigantesca, sendo a única instância de mediação da sociedade, e o individualismo se coloca como uma tentativa de romper com todas as políticas sociais que não passam pela relação mercantil. Nessa trilha, entende-se o empreendedorismo como uma das formas pelas quais o mercado se apropria de todas as horas da vida dos sujeitos que se aliam a essa proposta. A nosso ver, é um rótulo pomposo para trabalhadores qualificados, precarizados e iludidos, uma vez que o sonho de liberdade é objetivamente inviável (Tavares, 2018, p. 116).

A responsabilidade de garantir condições de sobrevivência dignas passa da esfera política e social para o nível individual, o que ocorre principalmente em países em desenvolvimento. 0 empreendedorismo surge, então, como uma solução emergente (Silva \& Bassani, 2007) e o empreendedor é concebido como o sujeito referencial da racionalidade neoliberal. O mercado engendra seu próprio sujeito, por meio de um processo de autoformação que é autoeducador e autodisciplinador, e define quais são as condutas. $O$ indivíduo liberal proclama sua autonomia, mas continua sendo parte de uma engrenagem nos grandes mecanismos neoliberais (Dardot \& Laval, 2016). O capital, por sua vez, é favorecido na ideologia neoliberal por tornar os trabalhadores em empresas (Tavares, 2018).

\section{Fatores que sustentam o crescimento do empreendedorismo}

Baron e Shane (2007) elencam três fatores que têm afetado o modo como o empreendedorismo tem sido aceito pela sociedade atual:

1. Disseminação de relatos empolgantes de empreendedores de sucesso pela mídia;

2. Reestruturação produtiva e alterações dos vínculos empregatícios;

3. Mudança nos valores.

Esses três fatores destacados por Baron e Shane (2007) podem ser explicados com base no pressuposto de que o empreendedorismo é uma ideologia neoliberal. A atenção recebida pelos empreendedores não é algo novo. No passado, entre os séculos XVIII e XIX, empreendedores já atraíam a atenção social devido às grandes fortunas acumuladas, alguns deles são: John Davison Rockefeller, que revolucionou o setor de petróleo em 1870 e criou a Standard Oil Company; Andrew Carnegie, responsável pela construção da primeira ponte que interligava a América, atravessando o rio Mississipi, e por diversas outras construções, investidor do setor ferroviário, petrolífero; e Cornelius Vanderbilt, que investiu na construção de ferrovias, além de outros negócios relacionados à marinha mercante (Baron \& Shane, 2007).

Atualmente, a mídia tem sido o veículo utilizado para disseminar os discursos de sucesso de empreendedores, formando um estereótipo do empreendedor relacionado a algo positivo e atraente. Em um momento carente de heróis políticos e militares, as pessoas os buscam em outros locais. Acreditam, assim, no empreendedorismo como meio para alcançar o sucesso com base em "modelos ideais" (Baron \& Shane, 2007).

Para disseminar esses "modelos ideais", a ideologia neoliberal conta com a indústria do management, representada pelas empresas de consultoria, escolas de administração, além de livros e revistas de gestão e negócios. Essa nova indústria vende o sonho de ascensão, de sucesso e reconhecimento (Wood, 2013). Por intermédio da ideologia do management e de sua fé inabalável nos valores do mercado, nos procedimentos racionais e no gênio do empreendedor, os valores empresariais invadem a vida pessoal (Wood, 2013), o que é disseminado como algo natural pelo empreendedorismo.

Em um trabalho recente, Ésther (2019) discutiu sobre a identidade do empreendedorismo articulando elementos da perspectiva crítica em psicologia social. $\mathrm{O}$ autor toma o empreendedorismo como um conceito estruturador da identidade, um conceito que assume um caráter ideológico e fetichizado ao definir um conjunto de crenças, comportamentos e características individuais que o empreendedor deve possuir e seguir. São estereótipos que ditam formas de ação (Ésther, 2019). 
Os estereótipos são, em sua maioria, representados pelas histórias de empresários de sucesso, que se constituem em um rico material para a difusão da ideologia do empreendedorismo. Os indivíduos tornam-se aprendizes de grandes trajetórias de vida. Nessas histórias, as personalidades bem-sucedidas são construídas de modo a traçar uma sequência linear e coesa da história pessoal (Leite \& Melo, 2008).

Os discursos do empreendedorismo funcionam como referência para a construção de identidades alinhadas a essa ideologia, evidenciando quais padrões de comportamento e de ação são aceitos, o que é reforçado e reproduzido por instituições e instâncias de socialização, que constroem o habitus em suas diversas camadas. Os sujeitos que não se enquadram nesses "modelos" tendem a ser excluídos. Para Ésther (2019), a ideologia do empreendedorismo torna-se ainda mais perversa ao atribuir ao indivíduo a responsabilidade por seu sucesso ou fracasso, camuflando qualquer referência ao caráter sócio-histórico e político da vida social (Ésther, 2019).

O segundo fator está relacionado à reestruturação produtiva e às novas formas de contratos empregatícios que surgiram. As novas configurações de vínculo entre empregadores e empregados tornaram os funcionários menos fiéis aos seus empregadores. Isso se intensificou na década de 1990, quando as grandes corporações norte-americanas cortaram mais de 6 milhões de empregos. Ao contrário do que se esperava, a taxa de desemprego nesse período caiu para os níveis mais baixos já registrados, o que pode ser explicado pelas novas empresas abertas por empreendedores - na verdade, trabalhadores que perderam seus empregos (Baron \& Shane, 2007).

Sobre esse aspecto, Ésther (2019) afirma que o discurso do empreendedorismo e a figura do empreendedor ganharam força com a reestruturação produtiva. A demissão de grandes contingentes levou as pessoas a buscarem novas formas de sobrevivência como alternativa ao emprego formal. Uma das saídas, conforme mencionado, foi a abertura de micro e pequenas empresas. Entretanto, o resultado foi um efeito precarizador do trabalho que se apresentou desde os primeiros anos e que permanece até os dias de hoje: "Esse processo levou à conformação de uma nova classe, o precariado - embora não apenas, mas uma mistura de precário e proletariado" (Ésther, 2019, p. 864).

A precarização é, no entanto, camuflada pelo discurso do empreendedorismo, que atribui ao empreendedor uma posição oposta à do mercado de trabalho formal assalariado, e enxerga este como opressor da criatividade e da autonomia do indivíduo. $O$ empreendedorismo prega a liberdade, opondo-se também à rotina e à burocracia (Leite \& Melo, 2008). Assim, surgem novos valores que são cultivados pelos indivíduos empreendedores, o que corresponde ao terceiro fator que sustenta o crescimento do empreendedorismo nos últimos anos, segundo a concepção de Baron e Shane (2007).

Tal fator refere-se à mudança de valores básicos. Buscar segurança, garantia do emprego e a construção de uma carreira sólida em uma mesma empresa não são mais expectativas dos trabalhadores. Os novos valores que surgiram, principalmente entre os jovens, baseiam-se na possibilidade de escolha em detrimento da certeza ou previsibilidade (Baron \& Shane, 2007). As garantias conferidas pelos diplomas de cursos superiores diminuíram e as aposentadorias estão ameaçadas. As carreiras também não são asseguradas. É preciso surgir um novo espírito do capitalismo que atenda às novas demandas para este permanecer como sistema dominante (Boltanski \& Chiapello, 2009).

\section{As características fundamentais do empreendedorismo como ideologia}

Dentre as principais características do empreendedorismo como ideologia, há um destaque para a questão da liberdade. A liberdade individual é um dos componentes fundamentais do mercado, contudo, neste contexto, a liberdade sem objetivo não é nada, ela só adquire valor pelo sistema que lhe dá os objetivos concretos, isto é, oportunidades de lucro (Dardot \& Laval, 2016).

De acordo com Gaulejac (2007, p. 57), "[...] a questão da liberdade não se coloca nos mesmos termos. Ela não se inscreve no mesmo espaço, na mesma temporalidade. Para uns, ela representa um conceito abstrato em um mundo globalizado; para os outros ela se inscreve concretamente em sua vida cotidiana".

A flexibilidade exigida pela ideologia neoliberal, em prol do progresso, soa aos ouvidos dos trabalhadores como horários irregulares, falta de regulamentação e proteção, isto é, flexibilização do trabalho (Gaulejac, 2007). Além da liberdade, outra característica fundamental do empreendedorismo como ideologia é a ideia de competição e concorrência. 0 mercado define-se por este caráter precisamente concorrencial, de competição, levando os indivíduos a acreditarem que estão 
em um jogo. Cada participante tenta superar o outro numa luta incessante para tornar-se líder e como tal permanecer (Dardot \& Laval, 2016).

Com a crise do capital, transfere-se para o sujeito a responsabilidade sobre sua vida, sua carreira, sua empregabilidade e seu bem-estar (Silva \& Bassani, 2007). Tal transferência é mais uma das doutrinas transmitidas pela ideologia neoliberal, a qual, segundo Gaulejac (2007), precisa de legitimidade para "[...] justificar as desigualdades que provoca e apagar as contradições que suscita". $O$ autor completa:

[...] o desemprego não é considerado como a consequência da defasagem estrutural entre o número de empregos criados pelo sistema econômico e o número de pessoas ativas suscetíveis a ocupar esses empregos. Ele resulta de "falhas de empregabilidade" de uma parte da população e, portanto, de sua "falta de adaptação" diante das necessidades da empresa. Nessa perspectiva, o problema do desemprego será resolvido incitando ou obrigando os desempregados a melhor "gerenciar suas competências" [...] (Gaulejac, 2007, p. 184).

O poder da racionalidade neoliberal deve-se à instauração de situações que forçam os indivíduos a funcionarem de acordo com os termos do jogo imposto por ela. O empreendedor de si é um sujeito formado para ganhar, para ser bem sucedido. É o homem da competição e do desempenho. Entretanto, a empresa de si tem duas faces: de um lado, o rosto triunfante do sucesso sem pudor; e de outro, o rosto deprimido do fracasso diante dos processos incontroláveis e das técnicas de renormalização. Neste jogo, todos imitam os melhores e progressivamente adquirem o "entrepreneurship" (Dardot \& Laval, 2016).

\section{Por que uma ideologia?}

O discurso da gestão empresarial, que é ao mesmo tempo formal e histórico, global e situado, mistura preceitos gerais e exemplos paradigmáticos e constitui atualmente a forma por excelência pela qual o espírito do capitalismo é incorporado e oferecido como algo que deve ser compartilhado (Boltanski \& Chiapello, 2009).

O empreendedorismo como uma ideologia é o que Oviedo e Misoscky (2017) expõem em seu trabalho. Segundo a concepção de Lukács (2012), apresentada pelos autores, a ideologia é uma forma de consciência que busca harmonizar interesses conflitantes e que implica praticamente o mundo concreto. As ideologias permitem uma coincidência entre interesses antagônicos, gerando um tipo de igualdade fictícia. Isso impede a luta social, pois impõe a falsa impressão de que a realidade é algo harmonioso.

Nesse mesmo sentido, Chauí (2014) apresenta a noção de ideologia como um conjunto lógico, sistemático e coerente de representações (ideias e valores) e de normas de conduta que indicam, prescrevem e regulamentam a conduta social. A ideologia tem caráter prescritivo e regulador, uma vez que fornece aos membros de uma sociedade dividida em classes uma explicação racional para as diferenças sociais, políticas e culturais, sem jamais atribuir tais diferenças à divisão da sociedade em classes e como consequência das divisões na esfera da produção econômica.

O objetivo da ideologia é ocultar a divisão social das classes, a exploração econômica, a dominação política e a exclusão cultural, e ela o faz por meio de referenciais identificadores, como a humanidade, a justiça, a liberdade, a igualdade, a nação. Chauí (2014) afirma que, desde o século XVII, com os avanços tecnológicos, surge a ideologia da competência. Isso significa que o poder passa a ser associado ao saber. Os discursos considerados válidos são disseminados por especialistas que ocupam uma posição na hierarquia organizacional. O "discurso competente" doutrina as pessoas sobre como se alimentar, se relacionar e criar seus filhos (Chauí, 2014). Sobre o empreendedorismo compreendido como uma ideologia, Ésther (2019) compartilha da definição do discurso competente de Chauí (2014), ao afirmar:

O empreendedorismo é um tema que a cada dia conquista mais espaço e adeptos quanto a seu significado, embora nem sempre de forma crítica e consciente. Isto pode implicar a difusão de uma ideologia, na medida em que se coloca o empreendedorismo como uma espécie de panaceia para todos os problemas econômicos e sociais de forma acrítica, constituindo aquilo que Chauí (2007) denomina discurso competente (Ésther, 2019, p. 858).

A ideologia da competência baseia-se na desigualdade entre os que possuem e os que não possuem o "saber" técnicocientífico, dando lugar à competição entre os indivíduos, dentre os quais a apenas alguns é reservado um lugar de sucesso. O discurso dos especialistas aponta que só há felicidade na competição e no sucesso de quem vence (Chauí, 2014). 
O teórico crítico Tragtenberg, ao discutir sobre a harmonia de interesses entre a indústria e a sociedade - levantada pelos teóricos clássicos da Administração-, define as teorias administrativas como ideologias. Por meio das técnicas de gestão, as teorias administrativas fornecem dispositivos que definem o homem como um ser meramente econômico e contribuem para a reprodução do sistema capitalista. Com as mudanças nas formas de produção evidenciadas a partir da década de 1970, as teorias administrativas renovaram-se, definindo o homem "empreendedor" como o responsável pelo seu próprio bem-estar. Diante do exposto, o empreendedorismo pode ser entendido como uma ideologia ligada ao neoliberalismo (Oviedo \& Misoscky, 2017).

Paes de Paula (2002) retoma as ideias trabalhadas por Tragtenberg em Burocracia e Ideologia no artigo "Tragtenberg revisitado: as inexoráveis harmonias administrativas e a burocracia flexível". Segundo a autora, Tragtenberg denunciou o caráter ideológico das teorias administrativas e realizou uma análise do pensamento weberiano, resgatando a ideia da burocracia como uma forma de dominação. As teorias administrativas já surgem com o objetivo de garantir a produtividade nas organizações, baseadas na ideia de harmonia entre a relação capital e trabalho, a despeito de ser inerentemente conflituosa (Paes de Paula, 2002).

Desse modo, as teorias administrativas dissimulam uma tensão natural entre os interesses de empresários e de trabalhadores. Além de favorecer a produtividade e a ordem, elas facilitam o monopólio do poder e as relações de dominação no mundo do trabalho, reduzindo as perspectivas de emancipação humana nas organizações (Paes de Paula, 2002). Com base no pensamento de Tragtemberg, Paes de Paula (2002) apresenta as quatro premissas relacionadas às teorias administrativas:

(1) São produtos dinâmicos das formações socioeconômicas de um determinado contexto histórico; ou seja, as teorias administrativas têm uma potencial capacidade de adaptação de acordo com as demandas capitalistas vigentes;

(2) Expressam-se de forma ideológica e operacional, e a ideologia manifesta-se por meio de ideias destituídas de história que disfarçam a verdadeira natureza da situação. Operam por meio de práticas, técnicas e ideias.

(3) Mesmo sendo adaptativas, obedecem a um princípio, uma herança cumulativa que é responsável pela sua criação e reelaboração;

(4) A burocracia é o dispositivo ideológico que congrega as teorias administrativas e também é produto e reflexo do contexto histórico e socioeconômico no qual está inserida.

A suposta "harmonia" sustentada pelas teorias administrativas caracteriza-se pela negação ou manipulação dos conflitos, em recorrência a uma abordagem positivista das relações sociais. Na visão de Tragtenberg apresentada por Paes de Paula (2002), isso ocorre por meio de mecanismos de controle social, sejam eles diretos ou indiretos.

A escola clássica da Administração representada por Taylor e Fayol também recorre a mecanismos de controle social. Num contexto de racionalização e intensificação do trabalho, os conflitos eram sufocados por mecanismos punitivos e métodos rígidos, como sanções e ameaças, para garantir a disciplina e evitar as resistências. Nessa primeira fase do capitalismo monopolista, buscava-se a harmonia entre as relações de trabalho pelo uso da força. Tais métodos abriram espaço para as contestações individuais e coletivas, fortalecendo o movimento sindical (Paes de Paula, 2002).

Para solucionar as falhas da escola clássica, surge a escola das relações humanas, que, segundo Paes de Paula (2002), revisitando Tragtenberg, apenas contribuíram para dar continuidade à ideologia da harmonia administrativa. A escola de relações humanas continua camuflando os conflitos ao substituir o uso da contenção direta pela manipulação e segue tributária do taylorismo ao manter a separação entre planejamento e execução de uma tarefa (Paes de Paula, 2002).

Na visão de Tragtenberg, a escola de relações humanas reproduzia, por meio dos departamentos de relações industriais e recursos humanos, uma "ideologia participacionista", estimulando uma falsa consciência nos funcionários de que são importantes para o processo decisório da organização, quando, na verdade, apenas obedecem a decisões já tomadas. Essa escola tende a culpar o indivíduo pelas tensões procedentes da relação entre capital e trabalho, impossibilitando que os conflitos sejam revelados (Paes de Paula, 2002).

Desse modo, é possível perceber como as duas principais escolas administrativas contribuíram de forma ideológica para a manutenção da harmonização entre as relações de trabalho, garantindo que os interesses do capital fossem alcançados. 
Além disso, Tragtenberg demonstrou como as teorias administrativas são dinâmicas e como herdam características de suas antecessoras (Paes de Paula, 2002).

Muito rígido para acomodar as novas tecnologias que estavam surgindo e as novas demandas do mercado consumidor, entra em crise o modelo fordista de produção em massa, o que gera transformações socioeconômicas que impactam a organização do trabalho. Assim, o capitalismo move-se para um novo paradigma de acumulação, a chamada acumulação flexível. Surgem organizações enxutas e flexíveis baseadas no modelo de produção japonês; ganham espaço as práticas de reengenharia, downsizing, terceirização, quarteirização, virtualização organizacional e empregos flexíveis (Paes de Paula, 2002).

Paes de Paula (2002) chama a atenção para o fato de que essas novas teorias não estão esvaziadas de ideologia: continuam perpetuando a harmonia nas relações trabalhistas e, consequentemente, a produtividade. $O$ toyotismo, modelo japonês de produção, baseia-se em ideias de cooperação, consenso, integração, participação e valorização de grupos informais para perpetuar essa ideologia. $O$ toyotismo representa uma adequação das teorias e práticas administrativas ao capitalismo flexível. Para alcançar a eficiência e a produtividade, esse modelo combina técnicas clássicas e práticas participativas, característica que reforça seu caráter ideológico e sinaliza sua herança das antigas escolas de administração (Paes de Paula, 2002).

Diante das perspectivas atuais associadas ao progresso tecnológico e à dificuldade em se construir uma sociedade democrática, a suposta liberdade do trabalhador ganha cada vez mais espaço. Nesse contexto, ideias como o ócio criativo e o empreendedorismo ganham cada vez mais adeptos que acreditam que é possível alcançar a liberdade ao abandonar as organizações e autogerenciar sua própria carreira como empreendedor (Paes de Paula, 2002).

Este modelo ganha forma em trabalhos autônomos, temporários e relações cada vez mais provisórias e flexíveis. Desse modo, consolida-se uma ideologia do empreendedorismo que extrapola as fronteiras das organizações e se entrelaça no tecido social. As técnicas de gestão não são mais restritas aos gestores, são de conhecimento geral, uma vez que todos devem gerir sua própria carreira. Isto reforça o culto à personalidade e ao sucesso, o qual, segundo Tragtenberg, é uma ilusão de liberdade que colabora para o aumento do individualismo, para a desmobilização política e para o distanciamento da vida democrática (Paes de Paula, 2002). Para Paes de Paula (2002), um dos maiores legados de Tragtenberg foi esse vigoroso alerta para as armadilhas ideológicas que criam uma ideia de harmonia e desviam os sujeitos dos caminhos da liberdade.

A noção clássica do empreendedorismo, que se referia ao papel de grandes empresários, é retomada pelo neoliberalismo para ser utilizada como uma forma de gestão de conflitos sociais (Puello-Socarrás, 2008). Com os discursos que estimulam o empreendedorismo, indivíduos desempregados e aqueles que possuem empregos precários são incentivados a se tornarem empreendedores. Isso evita o conflito social gerado pelo modo de produção capitalista em sua fase neoliberal. O novo cidadão torna-se responsável por sua participação na atividade produtiva e dedica seus esforços para conseguir sua subsistência, e não apresenta iniciativa para reivindicar seus direitos (Oviedo \& Misoscky, 2017).

A racionalidade neoliberal é utilizada pelo Estado como uma doutrina útil para a gestão dos conflitos sociais, na medida em que alivia o problema da precarização ao privilegiar o "eu" empreendedor. Assim, o empreendedorismo pode ser entendido como uma ideologia, uma vez que atende a uma função de harmonização dos conflitos sociais, resultantes dos antagonismos entre as classes. $\mathrm{O}$ empreendedorismo, que é historicamente entendido de várias formas, generaliza os interesses do capital para a totalidade social, levando as pessoas a buscar seu bem-estar individualmente (Oviedo \& Misoscky, 2017).

Diversas vertentes de pensamento confirmam a concepção do empreendedorismo como uma ideologia neoliberal. O trabalho de Hamann (2012) baseia-se em Biopolítica do poder, obra de Foucault, para fazer a crítica ao neoliberalismo e à subjetividade construída por ele: o "empreendedor de si". Seu trabalho ilustra a relevância da análise de Foucault sobre a governança neoliberal para uma compreensão crítica das transformações recentes na vida individual e social nos Estados Unidos, particularmente para a compreensão dos domínios público, privado, pessoal e político e de suas práticas.

A governamentalidade neoliberal é traduzida por Hamann (2012) como "a condução da conduta" pela criação estratégica de condições sociais que encorajam e exigem a produção de um sujeito neoliberal, uma subjetividade historicamente específica, caracterizada pela liberdade e autonomia. Para o autor, enquanto o liberalismo situa o "homem econômico" como um "homem de troca", o neoliberalismo visa ao "capital humano" composto por indivíduos convertidos em "empreendedores de si" que julgam e atuam baseados em valores mercantis. O "empreendedor de si" é seu próprio capital, seu próprio produtor e a fonte de seus próprios ganhos (Hamann, 2012). 
A "condução da conduta" promove formas opressivas de comportamento individual a serem interiorizadas pelos indivíduos, no entanto, em última análise, tais formas visam alcançar apenas os objetivos do capital. Assim, a ideologia do empreendedorismo busca assegurar que cada indivíduo seja responsável pelas metas de reprodução do sistema capitalista (Costa, Barros \& Carvalho, 2011).

Estado e mercado sempre foram dois modos de organização relativamente antagônicos, entretanto, com o neoliberalismo, eles se tornam dimensões compatíveis, com a preponderância de políticas favoráveis ao mercado (Puello-Socarrás, 2008). Para Hamann (2012), as decisões políticas são influenciadas pelos interesses privados sobrepostos a qualquer interesse público. Desse modo, o neoliberalismo obscurece, inverte ou elimina distinções tradicionais entre o público e o privado, entre o político e o pessoal. O autor toma o caso exemplar dos EUA para contextualizar sua teoria: por muitos anos os EUA privatizaram bens públicos tradicionais como parques, água, hospitais, escolas e presídios transformando-os em negócios com finalidade lucrativa, muitas vezes com promessas, nunca cumpridas, de servir aos interesses públicos. Como resultado da política adotada, um número cada vez maior de americanos carece de assistência à saúde e de educação de qualidade (Hamann, 2012).

Enquanto isso, as mazelas sociais se transferem para o domínio pessoal: pobreza, degradação ambiental, desemprego, falta de moradia, racismo, sexismo e heterossexismo - todos esses aspectos são reinterpretados como questões privadas que deveriam ser atendidas pela caridade voluntária, pela mão invisível do mercado, pelo cultivo de "sensibilidades" pessoais em relação aos outros ou pelo fortalecimento da própria autoestima (Hamann, 2012).

A grande contradição reside na distância existente entre os discursos populistas de liberdade, autonomia, individualismo e a realidade de que os indivíduos, em todo o mundo, estão cada vez mais sujeitos às severas, imprevisíveis e imperdoáveis demandas das forças de mercado e são avaliados por meios impessoais de cálculos de custo-benefício sobre riscos econômicos, responsabilidade financeira, produtividade, eficiência e conveniência (Hamann, 2012).

Desse modo, o sujeito pode declarar sua autonomia irredutível, entretanto, ele continua sendo apenas uma engrenagem dos grandes mecanismos neoliberais. Trata-se agora de governar um ser cuja subjetividade deve estar envolvida em torno da figura da empresa e dos princípios do mercado (Dardot \& Laval, 2016).

As organizações também estimulam o "empreendedor de si" por meio de práticas que promovem a plena responsabilidade dos trabalhadores por sua saúde e seu bem-estar, oferecendo incentivos aos funcionários para participação em treinamentos físicos, gestão de estilo de vida e programas de dieta. Além disso, o aumento das tecnologias de autoajuda dissemina técnicas de gestão de tudo, até mesmo de sentimentos (Hamann, 2012).

Leite e Melo (2008) afirmam que, desde a década de 1980, a institucionalização do empreendedorismo foi favorecida pela comercialização de pacotes gerenciais que popularizavam as teorias acadêmicas na mídia por meio de livros, jornais, revistas, vídeos, palestras, treinamentos, reality shows e jogos, cujos conteúdos visam guiar a conduta dos indivíduos, mostrando-lhes os comportamentos adequados a serem adotados. Os "conselhos" vão desde "como fazer algo" até imperativos do tipo "seja autoconfiante!". Os modelos de conduta são combinados de forma que o público não consiga fazer a distinção entre um e outro, absorvendo-os como um todo coerente de prescrição de ações e valores. Assim, uma visão de mundo é construída e incutida nos indivíduos (Leite \& Melo, 2008).

Tais receitas prontas contribuem para a hegemonia de conceitos, práticas e modelos ideais, que apresentam o empreendedor como um herói capaz de desbravar novos caminhos, incorporar o risco em suas ações, quebrar regras e enxergar oportunidades que ninguém mais além dele poderia fazê-lo (Costa, Barros \& Martins, 2012).

Diferentes técnicas e procedimentos visam capacitar os indivíduos a um maior "domínio de si". Estão normalmente relacionados a histórias, teorias e instituições, mas têm como ponto em comum o objetivo de fortalecer o eu, adaptá-lo melhor à realidade, torná-lo mais operacional em situações difíceis. Apresentam-se como saberes psicológicos, com um léxico especial, em autores de referência, metodologias particulares, tendo em vista reforçar uma argumentação racional e transformar os indivíduos por meio de um conjunto de premissas básicas. Todos estes métodos estão vinculados e servem para excluir a responsabilidade das normas da empresa no desempenho individual do trabalhador, alocando-as exclusivamente nos indivíduos (Dardot \& Laval, 2016). 


\section{CONSIDERAÇÕES FINAIS}

Este ensaio teórico teve como objetivo geral compreender a vertente neoliberal dos discursos do empreendedorismo e sua função de camuflagem da realidade das relações entre trabalho e capital. Buscou-se resgatar a história e a crítica ao empreendedorismo, refletindo sobre o tipo de racionalidade neoliberal veiculada pelos seus discursos, disseminados em forma de ideologia, como regras de conduta a serem seguidas sem questionamento. Desse modo, ocultam-se os conflitos relacionados ao ser empreendedor e ao crescimento do empreendedorismo.

O empreendedorismo alcançou seu auge com o aumento da concorrência global, o que resultou na falência de diversas empresas que não conseguiram manter-se neste novo contexto. As consequências foram cortes de pessoal (Baron \& Shane, 2007; Ésther, 2019). Ao perceber que as ideologias tradicionais não seriam eficazes no novo cenário, o capitalismo transformou-se e se adaptou, encontrando no empreendedorismo a solução para a crise do desemprego (Silva \& Bassani, 2007). O ideal de ser o dono do seu próprio negócio contagiou as mentes de muitos desempregados.

Entretanto, os discursos não contemplavam, e não contemplam, as contradições inerentes ao empreendedorismo. Os discursos que sustentam esta ideologia desconsideram os contextos e as realidades sociais dos empreendedores, colocando-os como meros instrumentos do capitalismo (Dardot \& Laval, 2016; Gaulejac, 2007). Esta é a conclusão deste estudo: o discurso do empreendedorismo voltado para a ideologia neoliberal isenta o Estado da responsabilidade de garantir mínimas condições de vida para esses indivíduos, colocando-os como responsáveis por seu sucesso ou fracasso, desconsiderando a importância das variáveis do contexto social no qual esses sujeitos estão inseridos.

Questiona-se, então, se há uma solução para essa realidade. Entende-se que é preciso estudar o fenômeno com todas as suas implicações sociais, culturais e políticas, considerando o empreendedor como um sujeito imerso em um contexto social que o influencia e é por ele influenciado. O contexto brasileiro, por exemplo, apresenta um empreendedorismo sustentado por pequenos negócios, em grande parte por negócios individuais voltados à sobrevivência. Ao considerar este aspecto, como modelos de sucesso podem ser impostos a esses sujeitos como uma forma de ser, viver e de se alcançar o sucesso, considerando que eles estão, geralmente, desempenhando uma atividade para sobreviver e inseridos em um contexto que não os favorece?

Ao contrário do que pregam esses discursos, os sujeitos não vivem em condições de igualdade para que sejam imbuídos de uma ideologia neoliberal que prega que ele deve ser o único responsável por seu sucesso ou fracasso. Desse modo, o que seria sucesso ou fracasso para um microempreendedor individual que recebe em torno de um salário mínimo por mês? Percebe-se uma grande lacuna entre a realidade vivida por esse sujeito e aquilo que é apregoado pelos discursos ideológicos neoliberais; entretanto é uma lacuna camuflada, um conflito solapado.

Considerando-se a magnitude do problema diante dos limites deste trabalho, reconhece-se impossibilidade de propor soluções práticas. Propõe-se, nesse caso, uma reflexão crítica acerca das características neoliberais dos discursos do empreendedorismo. Como trabalhos futuros, sugere-se investigar a situação brasileira do empreendedorismo do ponto de vista da realidade dos empreendedores. Além disso, seria relevante um aprofundamento crítico sobre temas que emergiram nos últimos anos, como o empreendedorismo feminino, o empreendedorismo social, startups e outras iniciativas que demonstrem o contexto social do empreendedor brasileiro. 


\section{REFERÊNCIAS}

Barlach, L. (2014). Comportamento empreendedor: Um estudo empírico baseado no referencial de McClelland. Revista de Carreiras e Pessoas, 4(3), 272-281.

Baron, R., \& Shane, S. A. (2007). Empreendedorismo: uma visão do processo. São Paulo, SP: Cengage Learning.

Birch, D. L. (1979). The job generation process. Cambridge, MA: MIT program on neighborhood and regional change.

Boava, D., \& Macedo, F. (2009). Sentido axiológico do empreendedorismo. In Anais do 33 Encontro Nacional da Associação Nacional de Pós-Graduação e Pesquisa em Administração, São Paulo, SP.

Boltanski, L., \& Chiapello, È. (2009). O novo espírito do capitalismo. São Paulo, SP: WMF Martins Fontes.

Bruyat, C., \& Julien, P. (2001). Defining the field of research in entrepreneurship. Journal of Business Venturing, 16(2), 165-180.

Cantillon, R. (1950). Ensayo sobre la naturaleza del comercio en general. México, Ciudad de México: Fondo de Cultura Económica.

Carvalho, L., \& Costa, T. (2015). Empreendedorismo: uma visão global e integradora. Lisboa, Portugal: Edição Sílabo.

Chauí, M. (2014). A ideologia da competência: escritos de Marilena Chauí. São Paulo, SP: Autêntica.

Colbari, A. L. (2015). Do autoemprego ao microempreendedorismo individual: desafios conceituais e empíricos. Revista Interdisciplinar de Gestão Social, 4(1), 165-189.

Cordeiro, A. T., \& Mello, S. C. B. (2006). Rupturas, permanências e ressignificações na estrutura discursiva do empreendedorismo. In Anais do 30 o Encontro da Associação Nacional de Pós-Graduação em Administração, Salvador, BA.

Costa, A. M., Barros, D. F., \& Carvalho, J. L. F. (2011). A dimensão histórica dos discursos acerca do empreendedor e do empreendedorismo. Revista de Administração Contemporânea, 15(2), 179-197.

Costa, A. M., Barros, D. F., \& Martins, P. E. M. (2012). A alavanca que move o mundo: o discurso da mídia de negócios sobre o capitalismo empreendedor. Cadernos EBAPE.BR, 10(2), 357-375.

Dardot, P., \& Laval, C. (2016). A nova razão do mundo: ensaio sobre a sociedade neoliberal (Tradução de Mariana Echalar). São Paulo, SP: Boitempo.

Dornelas, J. C. A. (2008). Empreendedorismo: Transformando ideias em negócios (3 ed.). Rio de Janeiro, RJ: Ed. Editora Campus-Elsevier Brasil.

Drucker, P. F. (1987). Inovação e espírito empreendedor: prática e princípios (Tradução de Carlos Malferrari, 2a ed.). São Paulo, SP: Pioneira.

Ésther, A. B. (2019). A política de identidade do empreendedorismo: uma análise na perspectiva da sociologia figuracional e da psicologia social crítica. Cadernos EBAPE.BR, 17(esp.), 857-870.

Filion, L. J. (1999). Empreendedorismo: empreendedores e proprietáriosgerentes de pequenos negócios. Revista de Administração, 34(2), 5-28.

Gaulejac, V. (2007). Gestão como doença social: ideologia, poder gerencialista e fragmentação social. São Paulo, SP: Editora Ideias \& Letras.
Global Entrepreneurship Monitor. (2018). Empreendedorismo no Brasil. Relatório executivo - 2017. Brasília, DF: Sebrae.

Hamann, T. H. (2012). Neoliberalismo, governamentalidade e ética. Ecopolítica, 3, 99-133.

Hoselitz, B. F. (1951). The early history of entrepreneurial theory. Explorations in Economic History, 3(4), 193-220.

Landström, H., Harirchi, G., \& Aström, F. (2012). Entrepreneurship: exploring the knowledge base. Research Policy, 41(7), 1154-1181.

Leite, E. (2012). O fenômeno do empreendedorismo. São Paulo, SP: Saraiva.

Leite, E. S., Melo, N. M. (2008). Uma nova noção de empresário: a naturalização do "empreendedor". Revista de Sociologia e Política, 16(31), 35-47.

Machado, H. P. V., \& Nassif, V. M. J. (2014). Réplica-Empreendedores: reflexões sobre concepções históricas e contemporâneas. Revista de Administração Contemporânea, 18(6), 892-899.

McClelland, D. C. (1961). The achieving society. New York, NY: D. Van Nostrand Company.

Natividade, D. R. (2009). Empreendedorismo feminino no Brasil: políticas públicas sob análise. Revista de Administração Pública, 43(1), 231-256.

Oviedo, C. F. T., \& Misoczky, M. C. A. (2017). La Ideología del Emprendimiento en el contexto del Posconflicto Colombiano. In Anales del 31 o Congreso de la Asociación Latinoamericana de Sociología, Montevideo, Uruguay.

Paes de Paula, A. P. (2002). Tragtenberg revisitado: as inexoráveis harmonias administrativas e a burocracia flexível. Revista de Administração Pública, 36(1), 127-144.

Puello-Socarrás, J. F. (2008). Nueva gramática del neo-liberalismo: itinerarios teóricos, trayectorias intelectuales, claves ideológicas. Bogotá, Colombia: Universidad Nacional de Colombia, Facultad de Derecho, Ciencias Políticas y Sociales.

Schumpeter, J. A. (1961). Capitalismo, Socialismo e Democracia (Tradução Ruy Jungmann). Rio de Janeiro, RJ: Editora Fundo de Cultura.

Shane, S., \& Venkataraman, S. (2000). The promise of entrepreneurship as a Field of research. Academy of Management Review, 25(1), 217-226.

Silva, L. F., \& Bassani, C. L. (2007). Evolucionismo: a face oculta do empreendedorismo. Brazilian Business Review, 4(1), 60-73.

Tavares, M. A. (2018). O empreendedorismo à luz da tradição marxista. Em Pauta: Teoria Social e Realidade Contemporânea, 16(41), 107-121.

Vale, G. M. V. (2014). Empreendedor: origens, concepções teóricas, dispersão e integração. RAC-Revista de Administração Contemporânea, 18(6), 874-891.

Verga, E., \& Silva, L. F. S. (2014). Empreendedorismo: evolução histórica, definições e abordagens. Revista de Empreendedorismo e Gestão de Pequenas Empresas, 3(3), 3-30.

Wood, T., Jr. (2013). Capitalismo Selvagem: Crônicas da vida corporativa e do trabalho. São Paulo, SP: Edição do Autor. 
Luana Jéssica Oliveira Carmo

ORCID: https://orcid.org/0000-0002-4943-0269

Mestre em Administração pelo Centro Federal de Educação Tecnológica de Minas Gerais (CEFET-MG). E-mail: luanajeoli@gmail.com

Lilian Bambirra de Assis

ORCID: https://orcid.org/0000-0002-1475-4183

Doutora em Administração pela Universidade Federal de Minas Gerais (UFMG); Professora no Centro Federal de Educação Tecnológica de Minas Gerais (CEFET-MG).E-mail: lilian@dcsa.cefetmg.br

Admardo Bonifácio Gomes Júnior ORCID: https://orcid.org/0000-0002-2349-0335

Doutor em Educação pela Universidade Federal de Minas Gerais (UFMG) e em Filosofia pela Aix-Marseille Université; Professor no Centro Federal de Educação Tecnológica de Minas Gerais (CEFET-MG).E-mail: admardo.jr@gmail.com

Marcella Barbosa Miranda Teixeira ORCID: https://orcid.org/0000-0002-6818-5561

Mestre em Administração pelo Centro Federal de Educação Tecnológica de Minas Gerais (CEFET-MG); Doutoranda em Administração pela Pontifícia Universidade Católica de Minas Gerais (PUC Minas). E-mail: marcellabmt@gmail.com 